\title{
Outcomes of Thyroid Surgery at Niamey National Hospital
}

\author{
Lassey James Didier1*, Maman Bachir Abdoulaye², Ousseini Adakal2, Harissou Adamou³, \\ Adama Saidou1, Ibrahim Amadou Magagi ${ }^{2}$, Kadi Idé1, Moussa Gagara4, Maarouf Malam5, \\ Taher Sidibé6, Rachid Sani1
}

\author{
${ }^{1}$ Department of Surgery and Surgical Specialties, National Hospital of Niamey, Faculty of Health Sciences of the University Abdou \\ Moumouni, Niamey, Niger \\ ${ }^{2}$ Department of Surgery and Surgical Specialties, Faculty of Health Sciences of the University of Maradi, Maradi, Niger \\ ${ }^{3}$ Department of Surgery and Surgical Specialties, Zinder National Hospital, Faculty of Health Sciences of the University of Zinder, \\ Zinder, Niger \\ ${ }^{4}$ Department of Anesthesia, Intensive Care and Emergencies, Niamey National Hospital, Niamey, Niger \\ ${ }^{5}$ Maternity Issaka Gazobi, Gynecology and Obstetrics Services, Niamey, Niger \\ ${ }^{6}$ Radiology Department at Niamey National Hospital, Niamey, Niger \\ Email: ${ }^{\star}$ jamesdidier3@gmail.com
}

How to cite this paper: Didier, L.J., Abdoulaye, M.B., Adakal, O., Adamou, H., Saidou, A., Magagi, I.A., Idé, K., Gagara, M., Malam, M., Sidibé, T. and Sani, R. (2021) Outcomes of Thyroid Surgery at Niamey National Hospital. Surgical Science, 12, 218-225.

https://doi.org/10.4236/ss.2021.127024

Received: June 17, 2021

Accepted: July 23, 2021

Published: July 26, 2021

Copyright $\odot 2021$ by author(s) and Scientific Research Publishing Inc. This work is licensed under the Creative Commons Attribution International License (CC BY 4.0).

http://creativecommons.org/licenses/by/4.0/ (c) (i) Open Access

\begin{abstract}
Introduction: Goiter is the most common endocrine disease in the world. The objective of our study is to assess and compare the morbidity linked to the surgical management of goiters and thyroid tumors in the general surgery department of the Niamey National Hospital. Result: We collected data on a prospective basis on 112 cases having undergone a thyroidectomy between March 2019 and April 2020. The female sex is predominant with $96.4 \%$, i.e. a sex ratio of 0.037 . The average age is 41.2 years with extremes ranging from 22 to 72 years old. The average duration of evolution of goiter is 7.5 years with extremes ranging from 5 months to 20 years old. The first reason for consultation is anterior cervical swelling. TSH testing confirmed euthyroidism in 107 patients (95.5\%). Therapeutically, loboisthmectomy is the most performed procedure with $43.7 \%$. The postoperative hormonal assessment revealed 32\% hypothyroidism at 6 months, with a significant difference for cases of total thyroidectomy. The occurrence of postoperative hypocalcemia was significantly greater after total and subtotal thyroidectomy. There is no significant difference in terms of recurrent complications. Conclusion: Thyroidectomies must be performed after adequate preparation and information to the patient on possible postoperative complications, hence the need for close medical monitoring immediately and remotely.
\end{abstract}

\section{Keywords}

Goiter, Thyroidectomy, Complications, Niamey, Niger 


\section{Introduction}

Classic thyroid surgery and minimally invasive or video-assisted surgery were the treatment of choice for goiters and thyroid tumors [1]. The main surgical indications are related to the existence of signs of compression, suspected malignancy and unsightliness [2]. Goiter is the most common endocrine disease in the world. In 1983, it was estimated that 320 million people worldwide were affected, and this number was probably underestimated. In endemic areas, which are areas of high iodine deficiency, its prevalence is enormous [2]. Niger is an endemic area and national prevalence of goiter in schools carried out in 1994 reports a prevalence of $35 \%$ to $60 \%$ of visible goiter [3]. This thyroid surgery is not without risk and can sometimes lead to complications. We report the results of the management of goiter and other thyroid tumors by comparing the various complications encountered in our department during thyroidectomies at the Notional Hospital in Niamey.

\section{Patients and Methods}

This is a cross-sectional descriptive study with a prospective aim ranging from March 2019 to April 2020, i.e. a period of 12 months. This work took place at the National Hospital of Niamey and more particularly in the general surgery departments. Included in the study were patients who had undergone surgery for thyroid disease during the study period. Patients admitted outside the period of this study and those operated on for non-thyroid disease were not included. For this work, ethical approval was obtained from the health authorities, the departments concerned and the patients.

A preoperative clinical examination was systematically performed to assess the age of the goiter, the existence and importance of clinical signs. The hormonal assessment included the determination of free T3, free T4, TSH. The preoperative work-up consisted of the determination of the blood and rhesus blood group, a glycemia, a creatinine level, a TCK, a neck X-ray, an ultrasound of the neck and a perioperative calcium level. Thyroid scintigraphy was performed in the event of a suspected thyroid nodule on ultrasound or hyperthyroidism. Also an indirect laryngoscopy was systematic preoperatively as well as a preparation for weak oral Lugol's iodine.

The medical preparation for the surgical act also concerned patients with hyperthyroidism. It consisted of the prescription of synthetic antithyroid drugs (Carbimazole), beta blockers (Propanolol) and sometimes tranquilizers.

The surgical technique consisted of an anterior cervicotomy with or without a section of the subhyaloid muscles, rigorous dissection of the inferior laryngeal nerves and the large parathyroids with the mention "inferior laryngeal nerve and parathyroids seen and not cut". Careful hemostasis ended the operation with closure on a suction Redon drain.

Postoperatively, it was essential to look for lower laryngeal involvement, hematoma or hemorrhage, signs of hypocalcemia or hypothyroidism. We per- 
formed laryngoscopy as needed, a thyroid hormone control and serum calcium at 1 month, 3 months, 6 months, 1 year postoperatively.

The variables studied are related to the epidemiological aspects, and the postoperative results in terms of morbidity of this type of surgery. Statistical chi-square tests were performed in order to determine the existence of association of the variables. The statistically significant threshold is retained for a value of $\mathrm{p}<0.05$.

The pitfalls encountered relate to the incomplete data and the number of missing persons, biasing the interpretation of the results.

\section{Results}

During the study period, we prospectively collected data on 112 cases who consulted for goiter or anterior cervical swelling of thyroid origin and who underwent thyroidectomy in the surgical department A of the Niamey National Hospital, between March 2019 and April 2020, i.e. 14 months. The frequency of thyroidectomies in the department represented 5.07\% $(\mathrm{N}=112)$ of the 2205 surgical procedures performed during our study period. These were 108 cases (96.4\%) of female sex, i.e. a sex ratio of 0.037 . The most affected age group is between 30 and 30 years with $37.5 \%$ of cases. The average age was 41.2 years with extremes ranging from 22 to 72 years old. The duration of the disease varied from 5 months to 20 years with an average of 7.5 years with different stages according to the WHO classification of goiters (see Table 1).

The goiter was multinodular in $64.3 \%(\mathrm{~N}=72)$ of cases, satellite lymphadenopathy was palpable in $2.6 \%$ of cases on physical examination.

TSH assay showed euthyroidism in 107 patients (95.5\%). Calcemia was normal in $96.4 \%$ of patients. Cervical radiography showed images of tracheal deviations and/or compression in 67 patients $(60 \%)$. Ultrasound revealed hyperechogenic images in 65 patients (58\%).

The preoperative diagnosis found multinodular goiter in 100 patients (89.2\%), 3 cases of Basedow (2.7\%), 2 hot nodules (1.8\%) and one cold nodule in 7 cases (6.3\%).

The surgical indications were dyspnea + dysphagia in $43.8 \%$ of cases, an unsightly cervical mass in $38.5 \%$, a isolated dyspnea in $10.7 \%$, a isolated dysphagia in $3.5 \%$, lymphadenopathy in $2.6 \%$ a compression dysphonia in $0.9 \%$. The types of actions performed are summarized (see Table 2).

Table 1. Distribution of patients according to the WHO classification of goiters.

\begin{tabular}{ccc}
\hline Class & Effective & Percentage (\%) \\
\hline OA & - & - \\
OB & 1 & 0.9 \\
I & - & 2 \\
II & 2 & 1.8 \\
III & 107 & 95.5 \\
Total & 112 & 100
\end{tabular}


Table 2. Table according to the method of excision.

\begin{tabular}{ccc}
\hline Type of intervention & Number of cases & Percentage (\%) \\
\hline Total thyroidectomy & 16 & 14.3 \\
Subtotal thyroidectomy & 38 & 33.9 \\
Loboisthmectomy & 58 & 41.8 \\
Total & 112 & 100 \\
\hline
\end{tabular}

The histologic examination carried out in 89 patients (79.5\%) confirmed a Macrovesicular adenomatous goiter in $70.8 \%(n=63)$, heterogeneous nodular goiter in $16.8 \%(\mathrm{n}=15)$, colloid nodular dystrophy in $2.2 \%(\mathrm{n}=2)$, Graves' disease $7.8 \%(\mathrm{n}=7)$, Dequervain's Thyroiditis in $1.2 \%(\mathrm{n}=1)$ and Papillary Carcinoma in $1.2 \%(\mathrm{n}=1)$.

Postoperative thyroid hormone monitoring at 6 months revealed 24 cases (21.4\%) of hypothyroidism, including 10 cases linked to total thyroidectomy, 8 linked to loboisthmectomy and 6 cases with subtotal thyroidectomy. After 1 year postoperatively, only 2 cases of hypothyroidism related to total thyroidectomy were reported despite hormonal substitution (see Table 3).

Only 75 patients performed their hormonal control 6 months after the operation.

Postoperative serum calcium monitoring was carried out in 79 patients and revealed moderate hypocalcaemia in the total thyroidectomy group in 6 patients (7.6\%) with a significant difference in the proportion of hypocalcaemia with other types of intervention. $(\mathrm{p}=0.04)$ (see Table 4$)$.

Transient unilateral paralysis of the inferior laryngeal nerves was observed in 2 cases of total thyroidectomy and 1 case of loboisthmectomy (see Table 5).

We recorded two cases of goiter recurrence after subtotal thyroidectomy which benefited from totalization.

\section{Discussion}

Thyroidectomies represent almost 5 , of the volume of activities of the surgical department A of the National Hospital of Niamey. Sani R. [3] in Niger reported 37 cases collected over 2 years in the same service in 2006; Toure A. [4] in Conakry found a frequency of $3.130 \%$ and Ozbas S. [1] in Turkey published a series of 750 patients over 7 years. This indicates an increase in the number of patients consulting in our surgery department for goiter and thyroid tumors in particular. The female sex is the majority representing 108 cases (96.4\%) with a sex ratio of 0.037 . This female predominance relative to a possible implication of hormonal factors in the genesis of this affection has been found by several authors [2] [3] [5]. Toure A. [4] in Conakry found 0.25. However Rios A. [6] in Spain reported male predominance with a sex ratio of 10.2. The average age of patients is 41.2 years with extremes ranging from 22 to 72 years. Sanogo [7] in Mali reported an average age of 39.74 years Thyroid disorders are therefore a disease of 
Table 3. Thyroid hormone check-up at 6 months depending on the type of intervention performed.

\begin{tabular}{cccc}
\hline \multirow{2}{*}{ Gestures } & \multicolumn{2}{c}{ Hormonal assessment } & \\
\cline { 2 - 4 } & Hypothyroidism & Euthyroidism & Total \\
\hline Total thyroidectomy & 10 & 4 & 14 \\
Subtotal thyroidectomy & 6 & 22 & 28 \\
Loboisthmectomy & 8 & 25 & 33 \\
Total & 24 & 51 & 75 \\
\hline
\end{tabular}

$\mathrm{p}=0.03$.

Table 4. Calcium control 3 months postoperatively.

\begin{tabular}{cccc}
\hline Type of intervention & Hypocalcemia & Normocalcemia & Total \\
\hline Total thyroidectomy & 6 & 10 & 16 \\
Subtotal thyroidectomy & 4 & 20 & 24 \\
Loboisthmectomy & 1 & 38 & 39 \\
Total & 11 & 68 & 79 \\
\hline
\end{tabular}

$\mathrm{p}=0.04$

Table 5. Unilateral lesions of the lower laryngeal nerves depending on the surgical procedure performed.

\begin{tabular}{cccc}
\hline \multirow{2}{*}{ Type of thyroidectomies } & \multicolumn{2}{c}{ Recurrent lesions } & Total \\
\cline { 2 - 4 } & YES & No & 16 \\
Total thyroidectomy & 2 & 14 & 38 \\
Subtotal thyroidectomy & 0 & 38 & 58 \\
Loboisthmectomy & 1 & 57 & 112 \\
Total & 3 & 109 & \\
\hline
\end{tabular}

$\mathrm{p}=0.07$.

young women. Other authors found that it was more a disease of postmenopausal women [2] [5] [8] [9].

The surgical indications were dominated by signs of compression such as dyspnea and dysphagia with $43.8 \%$ of cases. Sani R. [3] and Rios A. [5] also observed this predominance of signs of compression. The long period of evolution of the goiter could explain this predominance of compressive signs, knowing that the volume of the goiter increases over time [4] [7]. Patients like most African series, regardless of the disease, first try self-medication or even traditional treatment and only the failure of these therapies brings them back to modern medicine.

The preoperative hormonal assay confirmed euthyroidism in $95.5 \%$ of cases, our series being carried out in a context of endemic goiter.

Concerning the echographic aspects, according to the literature [10] the 
Table 6. Surgical procedures by authors.

\begin{tabular}{ccccc}
\hline & \multicolumn{4}{c}{ Surgical procedures } \\
\cline { 2 - 5 } Authors & $\begin{array}{c}\text { Total } \\
\text { thyroidectomy }\end{array}$ & $\begin{array}{c}\text { Lobectomy and/or } \\
\text { Loboisthmectomy }\end{array}$ & $\begin{array}{c}\text { Subtotal } \\
\text { thyroidectomy }\end{array}$ & Nodulectomy \\
\hline Sani et al. [3], 2006 & - & 7 cases (18.9\%) & 6 cases (81.1\%) & - \\
Toure [4], 2006 & 58 cases (30.21\%) & 127 cases (66.1\%) & 7 cases (3.65\%) & - \\
Koumare [11], 2002 & - & 216 cases (53.9\%) & 185 cases (41.6\%) & - \\
Rios [6], 2005 & 95 cases (85\%) & 8 cases (7\%) & 6 cases (5\%) & - \\
Dieng [12], 2010 & $12.7 \%$ & $38.6 \%$ & $39.8 \%$ & 7 cases (1.7\%) \\
Our study & 16 cases (14\%) & $\mathbf{5 8}$ cases (41.8\%) & $\mathbf{3 8}$ cases (34\%) & - \\
\hline
\end{tabular}

hyperechoic aspect, predominant in our series directed towards benignity, the heterogeneous aspect directed towards an adenoma or a cyst while the isoechogenic aspect would sometimes suggest a malignant goiter.

In terms of therapy, the surgical procedures performed are comparable to those of certain Nigerien and African authors (see Table 6).

Anathomopathological examination was performed in $79.5 \%$ of cases and revealed $98.8 \%$ of benign lesions, including $70.8 \%$ of cases of macrovesicular goiter and $16.8 \%$ of cases of heteronodular goiter. Malignant lesions represented only $1.2 \%$ of cases, it was papillary carcinoma. Ntyonga-pono [13] report $80 \%$ benign lesions, including 29\% macrovesicular colloid goiters and $16.03 \%$ microvesicular goiters, while Rios [6] in his series observed 3.7\% malignant lesion and Kang [8] with $3.08 \%$.

The correlation between the postoperative hormonal assessment at 6 months and the surgical procedure allowed us to observe a statistically significant difference $(p=0.03)$ in the occurrence of postoperative hypothyroidism between the total thyroidectomy group than the other procedures. This has been reported by several other studies [1] [14] [15]. The risk of hypothyroidism would be greater between 50\% and 75\% after thyroidectomy for Graves' disease [16].

The postoperative calcium level at 3 months revealed hypocalcemia mainly related to total thyroidectomy (50\%) and subtotal thyroidectomy (33.3\%); statistically significant difference $(\mathrm{p}=0.04)$ compared to other procedures. According to the literature, total thyroidectomy is more at risk of hypocalcemia than subtotal thyroidectomy [17].

With regard to recurrent lesions, we did not observe any significant difference between the different types of procedures performed $(p=0.07)$. A rigorous and standardized surgical technique makes it possible to reduce the risk of this paralysis [18]. Colak T. [19] in Turkey made similar observations.

\section{Conclusion}

Thyroid pathologies, dominated in our regions by probably endemic multinodular goiter, constitute a frequent pathology. Thyroid surgery, long feared for its 
complications, is nowadays performed with much more dexterity and thoroughness. Total thyroidectomy seems feasible to use with a greater risk of hypothyroidism and hypocalcemia than subtotal thyroidectomy. Recurrent damage is possible and must always be detected and taken care of.

\section{Conflicts of Interest}

The authors declare no conflicts of interest regarding the publication of this paper.

\section{References}

[1] Ozbas, S., Savas, K., Semih, A., et al. (2005) Comparison of the Complications of Subtotal near Total and Total Thyroidectomy in the Surgical Management of Multinodular Goiter. Endocrine Journal, 52, 199-205.

https://doi.org/10.1507/endocrj.52.199

[2] DeGroot, L.J. (2001) Treatment of Multinodular Goiter by Surgery. Journal of Endocrinological Investigation, 24, 820-822. https://doi.org/10.1007/BF03343934

[3] Sani, R., Adehossi, E., Kadre, S., et al. (2006) Evaluation of Surgical Treatment of Hyperthyroidism: Prospective Study on 37 Cases Operated on at Niamey Hospital in Niger. Medecine d'Afrique Noire, 53, 582-586.

[4] Toure, A., Diallo, A., Camara, L., et al. (2006) Thyroid Surgery: Experience of the General Surgery Department of the CHU Ignace Deen in Conakry. Mali Medical, 21, 23-26.

[5] Di Donna, V., Mario, G.S., Chiara de, W., et al. (2014) A New Strategy to Estimate Levothyroxine Requirement after Total Thyroidectomy for Benign Thyroid Disease. Thyroid, 24, 1759-1764. https://doi.org/10.1089/thy.2014.0111

[6] Rios, A., Rodriguez, J., Riquelme, J., et al. (2004) Prospective Study of Postoperative Complications after Total Thyroidectomy for Multinodular Goiters by Surgeons with Experience in Endocrine Surgery. Annals of Surgery, 240, 18-25. https://doi.org/10.1097/01.sla.0000129357.58265.3c

[7] Sanogo, Z.Z., Koita, A., Koumare, S., et al. (2012) Surgical Management of Hyperthyroid Goiters in Bamako. Mali Medical, 27, 1-4.

[8] Kang, A., Grant, C., Thompson, G., et al. (2002) Current Treatment of Nodular Goiter with Hyperthyroidism (Plummer's Disease): Surgery versus Radioiodine. Surgery, 132, 916-923. https://doi.org/10.1067/msy.2002.128691

[9] Drabo, Y., Kabore, J., Ouandaogo, J., et al. (1996) Cardiothyrosis in Ouagadougou: About 10 Cases. Medecine d Afrique Noire, 43, 615-618.

[10] Tagni-Zukami, D., Yomi, J., Monkam, G., et al. (1996) Ultrasound Aspects of Hypertrophic Pathology of the Thyroid Body at the Yaounde Military Hospital. Medecine d Afrique Noire, 43, 136-141.

[11] Koumare, A.K., Sissoko, F., Ongoiba, N., et al. (2002) Benign Goiter in Surgery in Mali: Apropos of 815 Cases. E-Mémoire National Academy of Surgery, 1, 1-6.

[12] Dieng, M., et al. (2010) Indications and Results of Thyroidectomies Performed in a General Surgery Department. About 402 Operated Patients. Revue Africaine de Chirurgie et Spécialités, 4, 5-10.

[13] Ntyonga-Pono, M., Nguizi-Ogoula, S., Mabika-Mabika, A., et al. (1998) Thyroid Tumors Operated on in Gabon, Anatomo-Pathological and Epidemiological Data: About 131 Cases. Medecine d' Afrique Noire, 45, 409-410. 
[14] Bilosi, M. and Binquet, C. (2002) Is Bilateral Subtotal Reduction Thyroidectomy Still Indicated in Graves' Disease? Annales de Chirurgie, 127, 115-120. https://doi.org/10.1016/S0003-3944(01)00689-7

[15] Chiara, D. (2010) Comparison between Thyroidectomiy and Hemithyroidectomy in Treatment of Single Thyroid Nodules Identified as Indeterminate Follicular Lesions by Fine-Needle Aspiration Cytology. Annali Italiani di Chirurgia, 81, 403-411.

[16] Farnell, M.B., Jonathan, A.H., William, M., et al. (1981) Hypothyroidism after Thyroidectomy for Graves' Disease. The American Journal of Surgery, 142, 535-538. https://doi.org/10.1016/0002-9610(81)90419-0

[17] Kennedy, T. (2003) Surgical Complications of Thyroidectomy. Operative Techniques in Otolaryngology-Head and Neck Surgery, 14, 74-79.

https://doi.org/10.1016/S1043-1810(03)90003-0

[18] Trésallet, C.C., Trésallet, J.-P. and Chigot, F. (2006) How to Prevent Recurrent Morbidity in Thyroid Surgery? Annals of Surgery, 131, 149-153.

https://doi.org/10.1016/j.anchir.2005.09.002

[19] Colak, T., Akca, T., Kanik, A., et al. (2004) Total versus Subtotal Thyroidectomy for the Management of Benign Multinodular Goiter in an Endemic Region. ANZ Journal of Surgery, 74, 974-978. https://doi.org/10.1111/j.1445-1433.2004.03139.x 